\title{
Effect of foot bathing on distal-proximal skin temperature gradient in elders
}

\author{
Wen-Chun Liao, ${ }^{\mathrm{a}, *}$, Carol A. Landis ${ }^{\mathrm{b}}$, Martha J. Lentz ${ }^{\mathrm{b}}$, Ming-Jang Chiu ${ }^{\mathrm{c}}$ \\ ${ }^{a}$ School of Nursing, Chun Shan Medical University, 110, Chien Kuo N. Rd, Sec. 1, Taichung 402, Taiwan \\ ${ }^{\mathrm{b}}$ School of Nursing, University of Washington, Seattle, USA \\ ${ }^{\mathrm{c}}$ Department of Neurology, National Taiwan University Hospital, Taipei, Taiwan
}

Received 4 October 2004; received in revised form 17 November 2004; accepted 30 November 2004

\begin{abstract}
Increased distal (foot)-proximal (abdominal) skin temperature gradient (DPG) has been associated with better sleep initiation. Warm footbath can affect distal skin temperature to change DPG. However, the optimum water temperature and duration necessary to raise DPG has not been established. This study explored the effects of 1-h foot bathing at two water temperatures of 40 and $41{ }^{\circ} \mathrm{C}$, respectively, on DPG in Taiwanese elders ( $n=6$, ages 60-73 years). Each subject's feet and legs were immersed in a temperature-controlled water tub to $20 \mathrm{~cm}$ above the ankles for $60 \mathrm{~min}$ in each of two water temperatures. Oral, abdominal, and foot temperatures were taken during (at 10-min intervals), and after (at 1min intervals) foot bathing. DPG was calculated by subtracting abdominal temperature from foot temperature. Results showed the value of DPG was significantly increased in the 10th min bathing at both water temperatures and maintained above $0{ }^{\circ} \mathrm{C}$. DPG gradually declined after bathing at both water temperatures. The value of DPG with $41{ }^{\circ} \mathrm{C}$ water was slightly higher than $40^{\circ} \mathrm{C}$. All subjects tolerated both bathing temperatures well for $1 \mathrm{~h}$. Both 40 and $41^{\circ} \mathrm{C}$ foot bathing for $1 \mathrm{~h}$ can increase the DPG and may be an effective way to affect whole body skin blood flow and trigger heat dissipation.
\end{abstract}

(C) 2005 Elsevier Ltd. All rights reserved.

Keywords: Body temperature; Distal-proximal skin temperature gradient; Footbath; Elder

\section{Introduction}

Sleep disturbances are common in older people. The overall prevalence of insomnia ranges from $14.0 \%$ to $42.2 \%$ in the general older population (Chiu et al., 1999; Foley et al., 1995; Kim et al., 2000; Newman et al., 1997;

\footnotetext{
*Corresponding author. Tel: + 886424730022 , ext 11736; fax: + 886424739030 .

E-mail addresses: wcl@csmu.edu.tw (W.-C. Liao), calandis@u.washington.edu (C.A. Landis), lentz@u.washington.edu (M.J. Lentz), mjchiu@ha.mc.ntu.edu.tw (M.-J. Chiu).
}

Ohayon, 1996, 1997; Ohayon and Zulley, 2001; Rocha et al., 2002). Sleep disturbances in older people are partially due to a decline of heat dissipation from the body core to the periphery. Interventions that enhance heat dissipation prior to sleep may improve sleep in older people.

\subsection{Distal-proximal skin temperature gradient is associated with rapid sleep onset}

Thermoregulation exhibits powerful interactions with sleep. Studies have shown that decreased core (rectal) temperature and increased distal (foot) temperature are 
associated with shortened sleep-onset latency (Krauchi and Wirz-Justice, 1994; van den Heuvel et al., 1998) and increased NREM sleep (Burgess et al., 2001). Decreased rectal temperature is induced by the vasodilatation of peripheral vessels in the skin, which produces an increase of distal temperature and facilitates heat loss from the core of the body to the periphery (Krauchi and Wirz-Justice, 2001). The gradient of temperature from proximal body sites (infraclavicular, thigh, stomach, forehead) to peripheral sites (feet and hands) is an indirect measure of heat dissipation or heat loss from the core to the periphery. This gradient of temperature is called distal-proximal skin temperature gradient (DPG). It has been used as a measure of skin blood flood and as an indirect index of distal heat loss (Krauchi et al., 1999). From observational studies, DPG (reaches $0{ }^{\circ} \mathrm{C}$ and above) is associated with sleepiness that occurs before sleep onset (van den Heuvel et al., 1998) and has been reported as the best predictor of the body's readiness for sleep (Krauchi et al., 2000, 1999; Krauchi and Wirz-Justice, 2001). Sleep latency (time to fall asleep) was significantly shorter when DPG value reached $0{ }^{\circ} \mathrm{C}$ before lights out.

\subsection{Local warming and $D P G$}

Skin blood flow plays an important role in body heat conservation and dissipation. Warming of skin causes vessel dilation and induces heat dissipation from the core to the periphery. It has been established that local temperature of $42{ }^{\circ} \mathrm{C}$ for $35-55 \mathrm{~min}$ causes maximal dilation of local skin blood vessels in adults ages 18-75 years old (Charkoudian, 2003; Kellogg et al., 1998; Minson, 2003; Taylor et al., 1984). Minson et al. (2001) demonstrated a typical biphasic skin blood flow during $50-80 \mathrm{~min}$ of $42{ }^{\circ} \mathrm{C}$ local heating of the right arm in healthy young adults. Skin blood flow was measured by cutaneous red blood cell flux via laser-Doppler. In their local heating protocol, skin temperature rapidly increased to $39-39.5^{\circ} \mathrm{C}$ and resulted in a fast increase in skin blood flow to an initial peak during the first 3-5 min, followed by a transient drop to a nadir, and then a secondary progressive rise to a plateau at $25-30 \mathrm{~min}$ of warming. After $50 \mathrm{~min}$ of warming, skin blood flow began to decline in some subjects. The local sensory nerves were involved in the initial rapid peak, whereas the nitric oxide mediated the second slow increase phase of skin blood flow (Charkoudian et al., 2002; Kellogg et al., 1998; Michikami et al., 2001; Minson et al., 2001; Roberts et al., 2002; Wilkins et al., 2003). The general pattern of cutaneous vasodilatation response to local warming at $42{ }^{\circ} \mathrm{C}$ was similar in both the older and young adults, but response was slower in older people than in young adults (Holowatz et al., 2003; Martin et al., 1995).
The above studies establish mechanisms of local warming on local skin blood flow as measured by local red blood cell flux. To our knowledge, no study has reported the effect of local warming on whole body skin blood flow as measured by DPG. We do not know if local warming can affect whole body vessel dilatation. Moreover, the sensory nerves involved in the first vasodilatation response are primarily c-fibre afferents, which are also nerves that conduct pain sensation. Heat sensation along with pain is vital to protect skin from acute damage. A diminished ability in nerve response to local warming makes older people susceptible to local tissue damage. Therefore, though $42^{\circ} \mathrm{C}$ local heating for 35-55 min can exhibit a maximum skin blood flow, such a high temperature may cause pain sensation and injury. Optimum water temperature and duration of local warming such as footbath to raise whole body skin blood flow has not been established. This study explored the effect of warm foot bathing at 40 and $41{ }^{\circ} \mathrm{C}$ water on skin blood flow measured by DPG in Taiwanese elders. Findings will guide the design of foot bathing intervention on the sleep quality in elders with insomnia.

\section{Methods}

\subsection{Design and procedures}

A crossover, single group design was used to explore the effect of foot bathing at two water temperatures for 60 min on changes of DPG. The study was conducted at the subjects' home. A specially designed foot water bath (Ten-Ta Co. Taipei, Taiwan) kept the water temperature at two temperature points: $40^{\circ} \mathrm{C}\left(104^{\circ} \mathrm{F}\right)$ or $41^{\circ} \mathrm{C}$ $\left(105.8^{\circ} \mathrm{F}\right)$ constantly. Participants were randomized to the sequence of water bath temperatures. Their feet and legs were immersed into the water bath to $20 \mathrm{~cm}$ above the ankles. There was at least $60 \mathrm{~min}$ apart between the two water temperatures. Timing for foot bathing was either at 2:00-6:30 pm or at 8:00-11:20 pm. Body temperatures were taken before, during, and after foot bathing. Tolerance, comfort level and heart rate, as well as physical symptoms were monitored during foot bathing. Their heart rate was maintained normally within 60-86 per minute with a mean of 72.7-75.3 per minute ( $\mathrm{SD}=4.8-9.9)$ during foot bathing. Ambient temperatures ranged from $28.6-30.2^{\circ} \mathrm{C}$ and humidity from $47 \%$ to $73 \%$.

\subsection{Participants}

Six older adults (three women post-menopause, three men) from 60 to 73 years of age residing in North Taiwan participated in this study. All participants were in good health status without psychiatric or medical 
diseases, including diabetes, peripheral vascular disease, neuropathy, or leg injuries or foot wounds.

Oral and written consent were obtained from all participants. University of Washington Human Subject Division and National Taiwan University Hospital Ethics Committee approved this study.

\subsection{Measures}

Oral (under tongue), abdominal (close to femoral artery), and foot (middle instep) temperatures were taken before, during, and after foot bathing. All temperatures were recorded before foot bathing, at 10min intervals during bathing with feet removed from water, and at 1-min intervals after bathing for $30 \mathrm{~min}$ with a four-channel Mini-Logger (Mini Metter Co., Inc., Bend, OR, USA). Both skin temperature probes (Nikkiso-YSI Co., Ltd. Tokyo, Japan) were covered by the Transpore surgical tapes or the Tegaderm transparent dressing (Nexcare, 3 M TM). Oral temperature represented core body temperature. Abdominal and foot skin temperatures represented proximal and distal skin temperatures, respectively. DPG was calculated by subtracting abdominal (proximal) temperature from foot (distal) temperature (Krauchi et al., 1999). The range of the Mini-Logger monitor for thermometer is $30-42^{\circ} \mathrm{C}$, with resolution of $0.05^{\circ} \mathrm{C}$ and accuracy of $0.1{ }^{\circ} \mathrm{C}$.

\subsection{Data analysis}

Sequential graphs were used in all oral, abdominal, and foot temperatures as well as the DPG to examine the distribution of body temperature before, during, and after foot bathing. A greater than $0{ }^{\circ} \mathrm{C}$ of the DPG was considered indicative of an effective water temperature for foot bathing. Paired- $t$ test was used to test mean body temperature differences between during bathing (at 10th, 20th, 30th, 40th, 50th, 60th $\mathrm{min}$ ) and before bathing (at 0th min). ANOVA repeated measure was used to examine the trends of body temperature between two water temperatures. Significance level was set at $p<0.05$, two tailed.

\section{Results}

All data expressed in text and tables are described as mean \pm SD. Body temperatures before and during foot bathing are listed in Table 1. Oral, abdominal, foot temperatures and DPG before bathing were not significantly different between 40 and $41^{\circ} \mathrm{C}$ water temperatures $(t=0.04-1.48$, all $P>0.05)$. With the $40{ }^{\circ} \mathrm{C}$ water temperature of footbath, oral temperatures taken throughout bathing did not increase significantly from before bathing $(t(5)<1.796, P>0.05)$. Abdominal and foot temperatures increased significantly after $20 \mathrm{~min}$ and 10 bathing, respectively. The value of DPG increased significantly after $20 \mathrm{~min}$ bathing. With the $41{ }^{\circ} \mathrm{C}$ bathing, significant increases of abdominal and foot temperatures, and DPG were similar to $40^{\circ} \mathrm{C}$ bathing (Table 1). However, oral temperatures significantly increased $0.37,0.50$, and $0.74{ }^{\circ} \mathrm{C}$ after 10,20 , and $50 \mathrm{~min}$ bathing, respectively. Oral temperatures before and during foot bathing increased with the $41{ }^{\circ} \mathrm{C}$ bathing, but remained constant with the $40{ }^{\circ} \mathrm{C}$ bathing (Fig. 1). ANOVA repeated measure showed no significant differences between these two trends $(F(1,10)=0.77, P=0.79)$.

The effect of foot bathing on DPG was similar at both water temperatures. The value of DPG elevated to above $0{ }^{\circ} \mathrm{C}$ after $10 \mathrm{~min}$ bathing and remained above

Table 1

Body temperatures before and during foot bathing

\begin{tabular}{|c|c|c|c|c|c|c|c|c|c|c|c|c|c|c|}
\hline \multirow[t]{2}{*}{ Warming (min) } & \multicolumn{2}{|l|}{0} & \multicolumn{2}{|l|}{10} & \multicolumn{2}{|l|}{20} & \multicolumn{2}{|l|}{30} & \multicolumn{2}{|l|}{40} & \multicolumn{2}{|l|}{50} & \multicolumn{2}{|l|}{60} \\
\hline & Mean & S.D. & Mean & S.D. & Mean & S.D. & Mean & S.D. & Mean & S.D. & Mean & S.D. & Mean & S.D. \\
\hline \multicolumn{15}{|l|}{$40^{\circ} \mathrm{C}$ warming } \\
\hline Oral & 35.85 & 0.48 & 36.19 & 0.68 & 36.06 & 0.50 & 36.13 & 0.50 & 36.35 & 0.43 & 36.05 & 0.86 & 36.02 & 0.70 \\
\hline Abdominal & 34.35 & 0.47 & 34.57 & 0.75 & $34.85 * *$ & 0.49 & $34.97 * * *$ & 0.50 & $35.14 * * *$ & 0.39 & $35.20 * * *$ & 0.34 & $35.23^{* * *}$ & 0.48 \\
\hline Foot & 33.71 & 0.82 & $35.37 *$ & 0.63 & $35.42 * * *$ & 0.68 & $35.33 * *$ & 0.52 & $35.63^{* *}$ & 1.04 & $35.69^{* *}$ & 0.66 & $35.92 * * *$ & 0.62 \\
\hline DPG & -0.64 & 0.63 & 0.79 & 1.32 & $0.57 * *$ & 0.54 & $0.36^{*}$ & 0.48 & $0.49^{*}$ & 0.92 & $0.57^{*}$ & 0.63 & $0.55^{* *}$ & 0.50 \\
\hline \multicolumn{15}{|l|}{$41^{\circ} \mathrm{C}$ warming } \\
\hline Oral & 35.60 & 0.63 & $35.98 *$ & 0.52 & $36.11^{*}$ & 0.44 & 35.88 & 0.64 & 36.05 & 0.17 & $36.34^{* *}$ & 0.45 & 36.23 & 0.50 \\
\hline Abdominal & 33.96 & 0.43 & 34.13 & 0.52 & $34.55^{* *}$ & 0.64 & $34.84 * *$ & 0.74 & $34.95^{* *}$ & 0.83 & 34.99 & 0.93 & $34.85^{* *}$ & 0.77 \\
\hline Foot & 33.34 & 0.24 & $35.01 *$ & 1.62 & $35.09 *$ & 1.51 & $35.30 *$ & 1.43 & $35.38 *$ & 1.89 & $35.61^{* *}$ & 1.23 & $35.46^{* *}$ & 1.35 \\
\hline DPG & -0.63 & 0.51 & $1.03^{*}$ & 1.15 & $0.76^{*}$ & 0.77 & $0.50^{*}$ & 0.96 & 0.47 & 1.96 & $0.62 *$ & 1.37 & $0.61^{*}$ & 1.24 \\
\hline
\end{tabular}

Paired- $t$ test was used to test differences between before bathing (at $0 \mathrm{~min}$ ) and during bathing (at 10th, 20th, 30th, 40th, 50th, 60th min). Paired- $t$ test, 2 tailed ${ }^{*} P<0.5,{ }^{* *} P<0.01,{ }^{* * *} P<0.001$. 


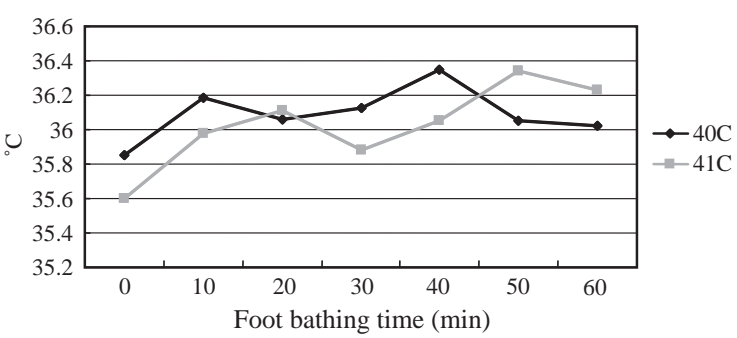

Fig. 1. Oral temperature before and during foot bathing.

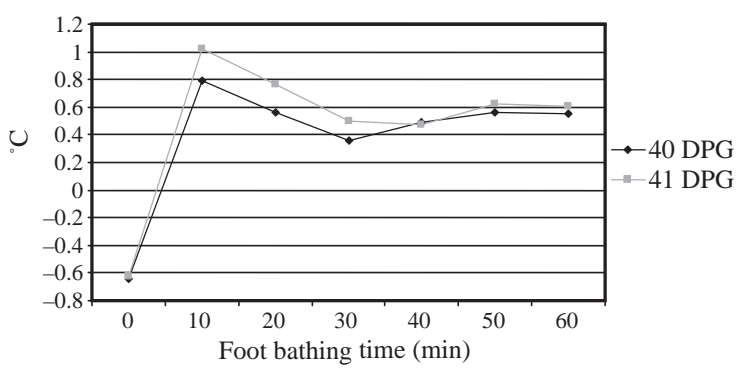

Fig. 2. DPG before and during foot bathing.

$0{ }^{\circ} \mathrm{C}$ during bathing (Table 1). The two mean DPG curves followed similar trends (Fig. 2). During bathing, there was a first peak DPG at 10th min, which decreased gradually to reach a nadir, and then increased slightly to reach the second peak. In the $41{ }^{\circ} \mathrm{C}$ curve, the nadir and the second peak of the DPG were at 40th min and 50th min (Fig. 2). In the $40{ }^{\circ} \mathrm{C}$ curve, the nadir and second peak of the DPG were at 30th $\mathrm{min}$ and 50th min, respectively (Fig. 2). ANOVA repeated measure showed no significant difference between these two trends $(F(1,10)=0.06, P=0.81)$. However, trends in Fig. 2 showed that the value of DPG reached a higher value with the $41{ }^{\circ} \mathrm{C}$ water than with $40{ }^{\circ} \mathrm{C}$. After bathing, both the DPG curves gradually declined (Fig. 3). With the $41{ }^{\circ} \mathrm{C}$ bathing, the value of DPG dropped to $0{ }^{\circ} \mathrm{C}$ after $8 \mathrm{~min}$ out of bathing and went back to the prebathing level after $23 \mathrm{~min}$ out of the footbath. With the $40^{\circ} \mathrm{C}$ water temperature of footbath, the value of DPG dropped to $0{ }^{\circ} \mathrm{C}$ and went back to the pre-bathing level after $4 \mathrm{~min}$ and $11 \mathrm{~min}$ out of the footbath, respectively (Fig. 3).

For subjective perception, participants expressed that they were warm, thirsty, and drowsy after 30-40 min of foot bathing. All subjects tolerated both bathing temperatures well for $1 \mathrm{~h}$.

\section{Discussion and implications}

DPG is an indirect measure of heat dissipation from the core to the periphery (Krauchi et al., 1999).

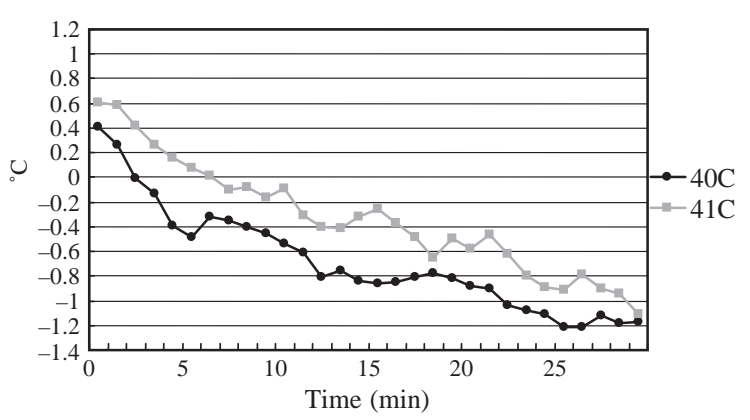

Fig. 3. DPG after foot bathing.

Increased value of DPG is associated with shorter sleep latency (Krauchi and Wirz-Justice, 1994; van den Heuvel et al., 1998). Data in our study showed that both 40 and $41^{\circ} \mathrm{C}$ foot bathing can elevate DPG value to above $0{ }^{\circ} \mathrm{C}$ after $10 \mathrm{~min}$ foot bathing suggesting that local distal warming can affect blood flow presumably to enhance heat dissipation and sleepiness. Foot bathing can be a potentially effective intervention to trigger heat dissipation and facilitate sleep in older people. Moreover, heart rate during foot bathing remained within normal range. This suggests that foot bathing is also a safe intervention for older people.

There are biphasic responses of local heating on local skin blood flow as measured by red cell flux (Minson et al., 2001). Using both 40 and $41^{\circ} \mathrm{C}$ foot bathing resulted in similar responses in whole body skin blood flow as measured by DPG. This provides an alternative and practical strategy in performing local heating and measuring skin blood flow. Measuring skin temperature is a non-invasive and easily performed procedure. By using DPG, health providers may be able to evaluate whole body skin blood flow.

Studies reported in the literature indicated that whole body heating increases both core temperature and skin blood flow, but local heating only increased skin blood flow without changing core temperature (Aoki et al., 1997; Charkoudian, 2003; Sung and Tochihara, 2000; Taylor et al., 1984). Our findings showed differential effects in that oral temperature remained constant before, during, and after foot bathing in $40{ }^{\circ} \mathrm{C}$ water temperature, but increased with $41^{\circ} \mathrm{C}$ footbath water temperature. Local warming of extremities, such as foot bathing, can add a heat load on the body. Since $40{ }^{\circ} \mathrm{C}$ water can increase skin blood flow without raising core temperature and not add heat to the whole body, while $41{ }^{\circ} \mathrm{C}$ footbath water temperature can provide heat load sufficient to increase core body temperature, the temperature of water in the footbath is very important. A lower footbath water temperature may be more effective than a higher temperature to induce heat dissipation and sleepiness. 
Local warming such as footbath does not necessarily affect core temperature, however, it can trigger distal vessel dilation to facilitate whole body circulation, hence aiding dissipation of body heat from the core to the periphery. In our study, the value of DPG at both water temperatures reached above $0{ }^{\circ} \mathrm{C}$. This is similar to the situation found in Krauchi's observational study in good sleepers (Krauchi et al., 1999). Participants in our study expressed drowsiness after $30-40 \mathrm{~min}$ of foot bathing. Following a warm footbath, in a suitable sleep environment including lights off, quiet, and a reclining position, people may be ready to fall asleep more easily.

Though $42{ }^{\circ} \mathrm{C}$ local heating results in maximum skin blood flow, such a high temperature may cause pain and induce stress in some individuals. Water temperatures of 40 and $41^{\circ} \mathrm{C}$ are more applicable as a potential aid to sleep on the daily basis. In our study, foot bathing at either 40 or $41^{\circ} \mathrm{C}$ effectively increased skin blood flow. However, $41{ }^{\circ} \mathrm{C}$ bathing exhibited higher DPG value than $40^{\circ} \mathrm{C}$ bathing. Though DPG after foot bathing at both water temperatures gradually declined, a footbath at $41{ }^{\circ} \mathrm{C}$ water temperature maintained a higher DPG value after following the footbath compared to the footbath at $40^{\circ} \mathrm{C}$ water temperature. It also took longer for the DPG to fall or return to baseline. Findings in this study were used in a study to examine effects of warm foot bathing on sleep quality.

\section{Acknowledgement}

This study was supported by the Hester McLaws Nursing Scholarship, University of Washington, School of Nursing, and the National Taiwan University Hospital, Department of Neurology.

\section{References}

Aoki, K., Kondo, N., Shibasaki, M., Takano, S., Katsuura, T., 1997. Circadian variation in skin blood flow responses to passive heat stress. Physiology \& Behavior 63 (1), 1-5.

Burgess, H.J., Holmes, A.L., Dawson, D., 2001. The relationship between slow-wave activity, body temperature, and cardiac activity during nighttime sleep. Sleep 24 (3), 343-349.

Charkoudian, N., 2003. Skin blood flow in adult human thermoregulation: how it works, when it does not, and why. Mayo Clinic Proceedings 78 (5), 603-612.

Charkoudian, N., Eisenach, J.H., Atkinson, J.L., Fealey, R.D., Joyner, M.J., 2002. Effects of chronic sympathectomy on locally mediated cutaneous vasodilation in humans. Journal of Applied Physiology 92 (2), 685-690.

Chiu, H.F., Leung, T., Lam, L.C., Wing, Y.K., Chung, D.W., Li, S.W., Chi, I., Law, W.T., Boey, K.W., 1999. Sleep problems in Chinese elderly in Hong Kong. Sleep 22 (6), 717-726.
Foley, D.J., Monjan, A.A., Brown, S.L., Simonsick, E.M., Wallace, R.B., Blazer, D.G., 1995. Sleep complaints among elderly persons: an epidemiologic study of three communities. Sleep 18 (6), 425-432.

Holowatz, L.A., Houghton, B.L., Wong, B.J., Wilkins, B.W., Harding, A.W., Kenney, W.L., Minson, C.T., 2003. Nitric oxide and attenuated reflex cutaneous vasodilation in aged skin. American journal of physiology. Heart and circulatory physiology 284 (5), H1662-H1667.

Kellogg Jr., D.L., Crandall, C.G., Liu, Y., Charkoudian, N., Johnson, J.M., 1998. Nitric oxide and cutaneous active vasodilation during heat stress in humans. Journal of Applied Physiology 85 (3), 824-829.

Kim, K., Uchiyama, M., Okawa, M., Liu, X., Ogihara, R., 2000. An epidemiological study of insomnia among the Japanese general population. Sleep 23 (1), 41-47.

Krauchi, K., Cajochen, C., Werth, E., Wirz-Justice, A., 2000. Functional link between distal vasodilation and sleep-onset latency? American Journal of Physiology and Regul. Integr. Comperative Physiology 278 (3), R741-R748.

Krauchi, K., Cajochen, C., Werth, E., Wirz-Justice, A., 1999. Warm feet promote the rapid onset of sleep. Nature 401 (6748), 36-37.

Krauchi, K., Wirz-Justice, A., 2001. Circadian clues to sleep onset mechanisms. Neuropsychopharmacology 25 (5 Suppl. 1), S92-S96.

Krauchi, K., Wirz-Justice, A., 1994. Circadian rhythm of heat production, heart rate, and skin and core temperature under unmasking conditions in men. American Journal of Physiology 267 (3 Pt 2), R819-R829.

Martin, H.L., Loomis, J.L., Kenney, W.L., 1995. Maximal skin vascular conductance in subjects aged 5-85yr. Journal of Applied Physiology 79 (1), 297-301.

Michikami, D., Iwase, S., Kamiya, A., Qi, F., Mano, T., Suzumura, A., 2001. Interrelations of vasoconstrictor sympathetic outflow to skin core temperature during unilateral sole heating in humans. Autonomic Neuroscience: Basic \& Clinical 91 (1-2), 55-61.

Minson, C.T., 2003. Hypoxic regulation of blood flow in humans. Skin blood flow and temperature regulation. Advances in Experimental Medicine and Biology 543, 249-262.

Minson, C.T., Berry, L.T., Joyner, M.J., 2001. Nitric oxide and neurally mediated regulation of skin blood flow during local heating. American Journal of Physiology 91 (4), 1619-1626.

Newman, A.B., Enright, P.L., Manolio, T.A., Haponik, E.F., Wahl, P.W., 1997. Sleep disturbance, psychosocial correlates, and cardiovascular disease in 5201 older adults: the Cardiovascular Health Study. Journal of the American Geriatrics Society 45 (1), 1-7.

Ohayon, M., 1996. Epidemiological study on insomnia in the general population. Sleep 19 (Suppl. 3), S7-S15.

Ohayon, M.M., 1997. Prevalence of DSM-IV diagnostic criteria of insomnia: distinguishing insomnia related to mental disorders from sleep disorders. Journal of the Psychiatric Research 31 (3), 333-346.

Ohayon, M.M., Zulley, J., 2001. Correlates of global sleep dissatisfaction in the German population. Sleep 24 (7), 780-787. 
Roberts, M., Rivers, T., Oliveria, S., Texeira, P., Raman, E., 2002. Adrenoceptor and local modulator control of cutaneous blood flow in thermal stress. Comparative Biochemistry and Physiology. Part A. Molecular \& Integrative Physiology 131 (3), 485-496.

Rocha, F.L., Uchoa, E., Guerra, H.L., Firmo, J.O.A., Vidigal, P.G., Lima-Costa, M.F., 2002. Prevalence of sleep complaints and associated factors in community-dwelling older people in Brazil: the Bambui Health and Ageing Study (BHAS). Sleep Medicine 3 (3), 231-238.

Sung, E.J., Tochihara, Y., 2000. Effects of bathing and hot footbath on sleep in winter. Journal of Physiology and Anthropology Applied and Human Science 19 (1), 21-27.
Taylor, W.F., Johnson, J.M., O’Leary, D., Park, M.K., 1984. Effect of high local temperature on reflex cutaneous vasodilation. Journal of Applied Physiology 57 (1), 191-196.

van den Heuvel, C.J., Noone, J.T., Lushington, K., Dawson, D., 1998. Changes in sleepiness and body temperature precede nocturnal sleep onset: evidence from a polysomnographic study in young men. Journal of Sleep Research 7 (3), 159-166.

Wilkins, B.W., Holowatz, L.A., Wong, B.J., Minson, C.T., 2003. Nitric oxide is not permissive for cutaneous active vasodilatation in humans. Journal of Physiology 548 (Pt 3), 963-969. 